\title{
Violacein induces p44/42 mitogen-activated protein kinase-mediated solid tumor cell death and inhibits tumor cell migration
}

\author{
TORAL MEHTA $^{1}$, KOEN VERCRUYSSE $^{2}$, TERRANCE JOHNSON ${ }^{1}$, \\ ANTHONY OKECHUKWU EJIOFOR ${ }^{1}$, ELBERT MYLES ${ }^{1}$ and QUINCY ANTOINE QUICK ${ }^{1}$ \\ Departments of ${ }^{1}$ Biological Sciences and ${ }^{2}$ Chemistry, Tennessee State University, Nashville, TN 37209, USA
}

Received January 25, 2015; Accepted February 27, 2015

DOI: $10.3892 / \mathrm{mmr} .2015 .3525$

\begin{abstract}
Microbial secondary metabolites have emerged as alternative novel drugs for the treatment of human cancers. Violacein, a purple pigment produced by Chromobacterium violaceum, was investigated in the present study for its anti-tumor properties in tumor cell lines. Clinically applicable concentrations of violacein were demonstrated to inhibit the proliferative capacity of tumor cell lines according to a crystal violet proliferation assay. The underlying mechanism was the promotion of apoptotic cell death, as indicated by poly(ADP ribose) polymerase cleavage and p44/42 mitogen-activated protein kinase signaling determined by western blot analysis. Collectively, this provided mechanistic evidence that violacein elicits extracellular-signal regulated kinase-induced apoptosis via the intrinsic pathway. The anti-malignant properties of violacein in the present study were further demonstrated by its inhibitory effects on brain tumor cell migration, specifically glioblastomas, one of the most invasive and therapeutically resistant neoplasms in the clinic. Additionally, solid tumors examined in the present study displayed differential cellular responses and sensitivities to violacein as observed by morphologically induced cellular changes that contributed to its anti-migratory properties. In conclusion, violacein is a novel natural product with the potential to kill several types of human tumor cell lines, as well as prevent disease recurrence by antagonizing cellular processes that contribute to metastatic invasion.
\end{abstract}

\footnotetext{
Correspondence to: Dr Quincy Antoine Quick, Department of Biological Sciences, Tennessee State University, 3500 John A. Merritt Boulevard, Nashville, TN 37209, USA

E-mail: qquick@tnstate.edu
}

Key words: violacein, apoptosis, migration, poly(ADP ribose) polymerase, $\mathrm{p} 44 / 42$

\section{Introduction}

The utility of bacteria as agents for the treatment of cancer was described over a century ago and continues to be investigated for their therapeutic value as delivery agents for anti-cancer drugs and vectors for gene therapy (1-3). Additionally, contemporary strategies have also studied the use of bacterial products, including proteins, enzymes, immunotoxins and secondary metabolites for their anti-tumor properties (1-3). An advantage of these alternatives is the lack of systemic infection associated with the use of live, attenuated and engineered bacterial strains for cancer therapy (1-3).

In the present study, the secondary metabolite violacein, a pigment produced by the bacteria Chromobacterium violaceum, was investigated as an anti-tumor agent, which has been shown to have medicinal applications as an antibiotic and anti-trypanosoma agent $(4,5)$. The use of bacterial metabolites such as violacein as anti-cancer agents is supported by pre-clinical studies with other microbial products, including farnesyltransferase inhibitors (6-14), prodigines (15-17) and epothilones (18-22), which have displayed positive therapeutic efficacy in several types of cancer and were subsequently examined in phase I and II clinical trials. More specifically, violacein has been shown to have anti-cancer properties in leukemia $(23,24)$ and colon cancer cells $(25-27)$, as well as in Ehrlich ascites tumors by Bromberg et al (28) using an in vivo mouse model. In contrast to these studies, the present study used violacein extracted from a Chromobacterium violaceum strain native to a copper basin in Tennessee, which was demonstrated here to have anti-proliferative effects on cell lines derived from solid tumors, as well as displayed an inhibitory effect on cancer cell migration, extending the anti-tumorigenic properties of this bacterial-produced metabolite.

\section{Materials and methods}

Cell conditions and reagents. U87 (glioblastoma), A549 (lung) and MCF7 (breast) cancer cells were purchased from the American Type Culture Collection (Manassas, VA, USA). All cell lines were maintained in Dulbecco's Modified Eagle's Medium (DMEM; Invitrogen Life Technologies, Carlsbad, CA, USA) containing 10\% fetal bovine serum (Invitrogen 
Life Technologies), $2 \mathrm{mM}$ L-glutamine (Invitrogen Life Technologies), $100 \mathrm{nM}$ MEM non-essential amino acids (Invitrogen Life Technologies) and penicillin-streptomycin (Invitrogen Life Technologies) at $37^{\circ} \mathrm{C}$ and $5 \% \mathrm{CO}_{2}$.

Isolation and characterization of violacein. Chromobacterium violaceum was collected from environmental soil and water samples at the Tennessee Copper Mining Company site (Ducktown, TN, USA), also termed the Copper Basin. Chromobacterium violaceum were inoculated in LuriaBertani broth (LB) media, streaked and grown on agar plates for $48 \mathrm{~h}$ at $30^{\circ} \mathrm{C}$, until colonies formed. The colonies were subsequently selected and grown as cultures in LB broth media for $24-48 \mathrm{~h}$ at $30^{\circ} \mathrm{C}$. The cultures were used to extract and purify violacein, as described previously (29). Cultures were centrifuged at $14,629 \mathrm{xg}$ in $100 \%$ ethanol for $15 \mathrm{~min}$ at $4^{\circ} \mathrm{C}$ and the supernatant was collected, and violacein was separated and extracted using chloroform. The violacein was allowed to dry for $24 \mathrm{~h}$ and dissolved in 50\% ethanol (Fisher Scientific, Fair Lawn, NJ, USA). Violacein was subsequently purified with reverse phase column chromatography and characterized by liquid chromatography-mass spectrometry and ultraviolet-visible spectroscopy.

Crystal violet cell proliferation assay. Cells were plated in 24 -well plates, treated with $250 \mathrm{nM}, 500 \mathrm{nM}$ and $1 \mu \mathrm{M}$ violacein and allowed to incubate for $48 \mathrm{~h}$ ([vehicle controls were treated with dimethyl sulfoxide (DMSO; Amresco, LLC, Solon, OH, USA)] for dose-response experiments. For time-course experiments, cells were treated with $1 \mu \mathrm{M}$ violacein and allowed to incubate for 1, 3 and 5 days. Subsequently, tissue culture medium was removed, the cell monolayer was fixed with $100 \%$ methanol for $5 \mathrm{~min}$ and stained with $0.5 \%$ crystal violet in $25 \%$ methanol for $10 \mathrm{~min}$. Cells were then washed three times for $5 \mathrm{~min}$ each with distilled water to remove excess dye and allowed to dry overnight at room temperature. The incorporated dye was then solubilized in $0.1 \mathrm{M}$ sodium citrate (Sigma-Aldrich; St. Louis, MO, USA) in 50\% ethanol. Next, $100 \mu \mathrm{l}$ treated and control samples were transferred to 96-well plates and optical densities read at $540 \mathrm{~nm}$ using an X-mark microplate absorbance spectrophotometer (Bio-Rad, Hercules, CA, USA).

Cell motility. Motility assays were conducted according to the manufacturer's instructions (Cell Biolabs Inc., San Diego, CA, USA). A cell suspension containing $0.5-1.0 \times 10^{6}$ cells $/ \mathrm{ml}$ was prepared in serum-free media with vehicle (DMSO) or $1 \mu \mathrm{M}$ violacein, while $500 \mu \mathrm{l}$ of media containing $10 \%$ fetal bovine serum was added to the lower chamber of the migration plate. $300 \mu \mathrm{l}$ of the cell suspension containing vehicle or $1 \mu \mathrm{M}$ violacein was then added to the inside of each insert and allowed to incubate for 24 hours at $37^{\circ} \mathrm{C}$ and $5 \% \mathrm{CO}_{2}$. Subsequently, non-migratory cells were removed from the plate inserts (per manufacturer's instructions), migratory cells were counterstained, solubilized, and optical density densities read at $595 \mathrm{~nm}$ using a X-mark microplate absorbance spectrophotometer (Bio-Rad Laboratories).

Western blot analysis. Cells were plated and treated with $1 \mu \mathrm{M}$ violacein for $24 \mathrm{~h}$ or vehicle (DMSO), rinsed with
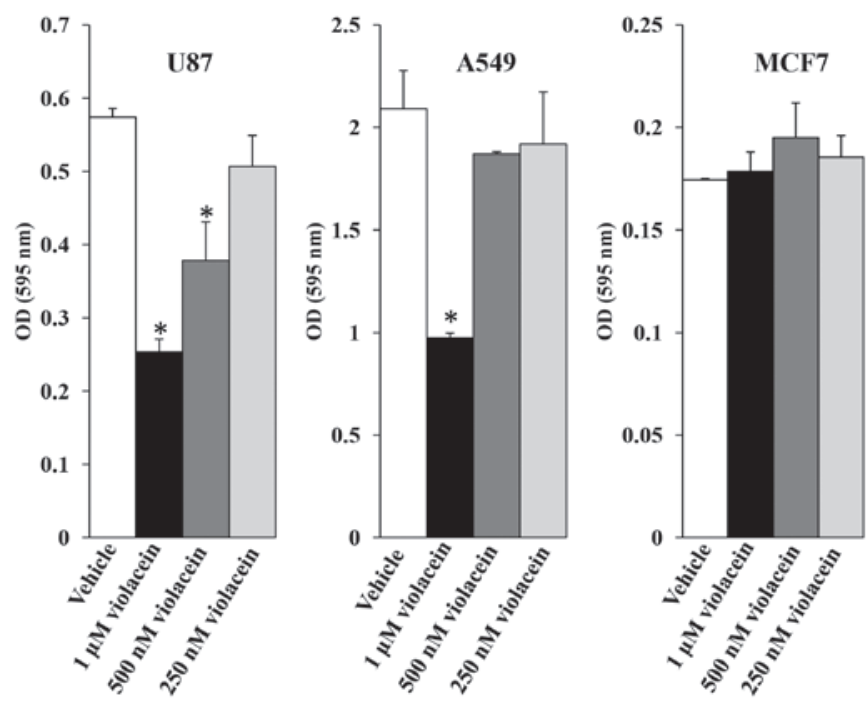

Figure 1. Dose response and sensitivity of solid tumor cell lines to violacein. Violacein caused a significant decrease in cell viability of U87 brain tumor cells and A549 lung cancer cells in contrast to MCF7 breast cancer cells. Shown is a dose-response experiment performed in duplicate representative of three independent experiments that showed similar results. White bars, vehicle dimethyl sulfoxide; black bars, $1 \mu \mathrm{M}$ violacein; dark grey bars, $500 \mathrm{nM}$ violacein; light grey bars, $250 \mathrm{nM}$ violacein. Error bars represent the standard error. ${ }^{*} \mathrm{P}<0.05$ compared to vehicle-treated control cells.

phosphate-buffered saline (Bio-Rad Laboratories, Hercules, CA, USA), and lysed with CelLytic M Cell lysis reagent (Sigma-Aldrich, St Louis, MO, USA). Protein concentrations were subsequently determined using the Bradford reagent (cat. no. B6916; Sigma-Aldrich). Proteins were separated by 8\% SDS-PAGE (Bio-Rad Laboratories) and then transferred to nitrocellulose membranes. For immunoblotting, nitrocellulose membranes were incubated with phosphorylated (p) Akt (rabbit monoclonal; cat. no. 4606), cleaved poly(ADP ribose) polymerase (PARP; rabbit polyclonal; cat. no. 9544), p44/42 (rabbit monoclonal; cat. no. 4370), and pS6-ribosomal protein (rabbit monoclonal; cat. no. 4858) and $\beta$-actin (rabbit polyclonal; cat. no. 4967), purchased from Cell Signaling Technology (Danvers, MA, USA) and all diluted 1:25, recognizing target proteins overnight at $4^{\circ} \mathrm{C}$. The membranes were then incubated with a horseradish peroxidase-conjugated goat anti-rabbit secondary antibody (1:100; cat. no. 7074; Cell Signaling Technology) for $3 \mathrm{~h}$ at room temperature, analyzed using an enhanced chemiluminescence detection system with SuperSignal West Pico Chemilluminescent Substrate (cat. no. 34080; Thermo Fisher Scientific, Waltham, MA, USA) and visualized by autoradiography using a BioSpectrum UVP Imaging System (BioSpectrum, Upland, CA, USA). Actin was used as loading control.

Statistical analysis. Values are expressed as the mean \pm standard error. Significance was determined using Student's t-test. $\mathrm{P}<0.05$ was considered to indicate a statistically significant difference between values.

\section{Results}

Violacein antagonizes brain, lung and breast cancer cell proliferation. Lung and breast cancer are two of the most 

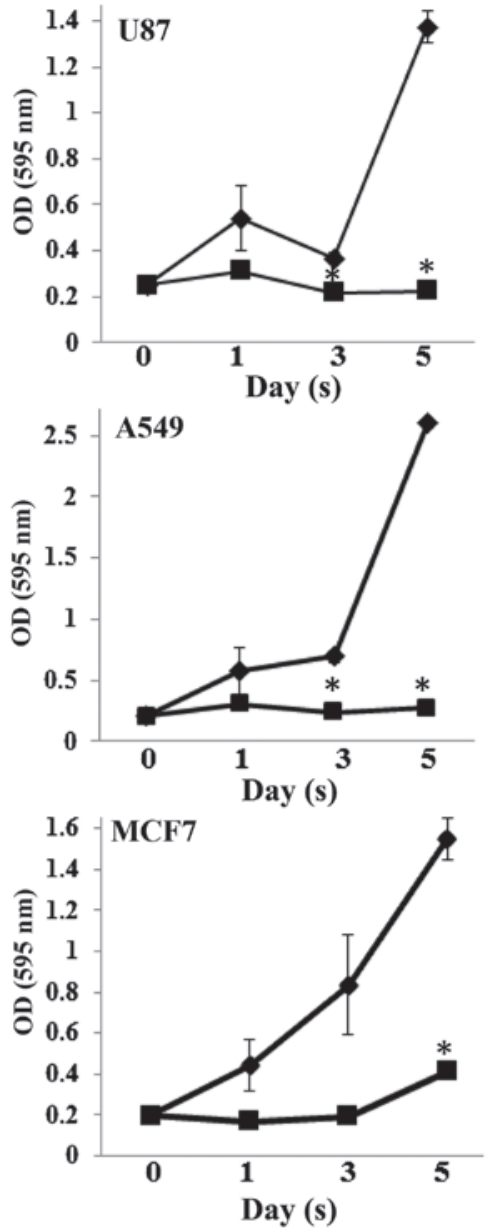

Figure 2. Anti-proliferative effects of violacein on cancer cells. The mitotic capacity of U87 brain tumor and A549 lung cancer cells was inhibited in response to treatment with $1 \mu \mathrm{M}$ violacein, while violacein decreased the proliferative rate of MCF7 breast cancer cells. Values are representative of three independent experiments performed in duplicate that showed similar results. Diamonds, vehicle dimethyl sulfoxide; squares, $1 \mu \mathrm{M}$ violacein. Error bars represent the mean \pm standard error. ${ }^{*} \mathrm{P}<0.05$ compared to vehicle-treated control cells at the corresponding time-point. OD, optical density.

common types of cancer found in men and women, and have high incidence of metastasis to the brain (30). The present study therefore evaluated the effects of violacein on three solid tumor cell lines, U87 (brain), A549 (lung) and MCF7 (breast). Dose-response experiments were performed at the outset to assess the effects of several violacein concentrations ( $250 \mathrm{nM}, 500 \mathrm{nM}$ and $1 \mu \mathrm{M}$ ) on cell viability. Cell viability dose-response assays revealed a 56-, 34- and 12\%-decrease in U87 cells treated with $1 \mu \mathrm{M}, 500 \mathrm{nM}$ and $250 \mathrm{nM}$ violacein as compared to the viability of vehicle treated control cells, respectively, while A549 cells displayed a 54, 11 and $8 \%$-decrease in viability when treated with identical concentrations compared to that of vehicle-treated control cells (Fig. 1). By contrast, MCF7 cell viability did not decrease in response to violacein exposure using this assay.

The anti-proliferative effects of violacein have been attributed to its ability to elicit a cytotoxic response in several human cancers $(23,27,31-33)$, as well as induce differentiation, a cytostatic response observed in leukemia cells by Melo et al (26). To gain better insight into the effect of violacein on cell proliferation in brain, lung and breast

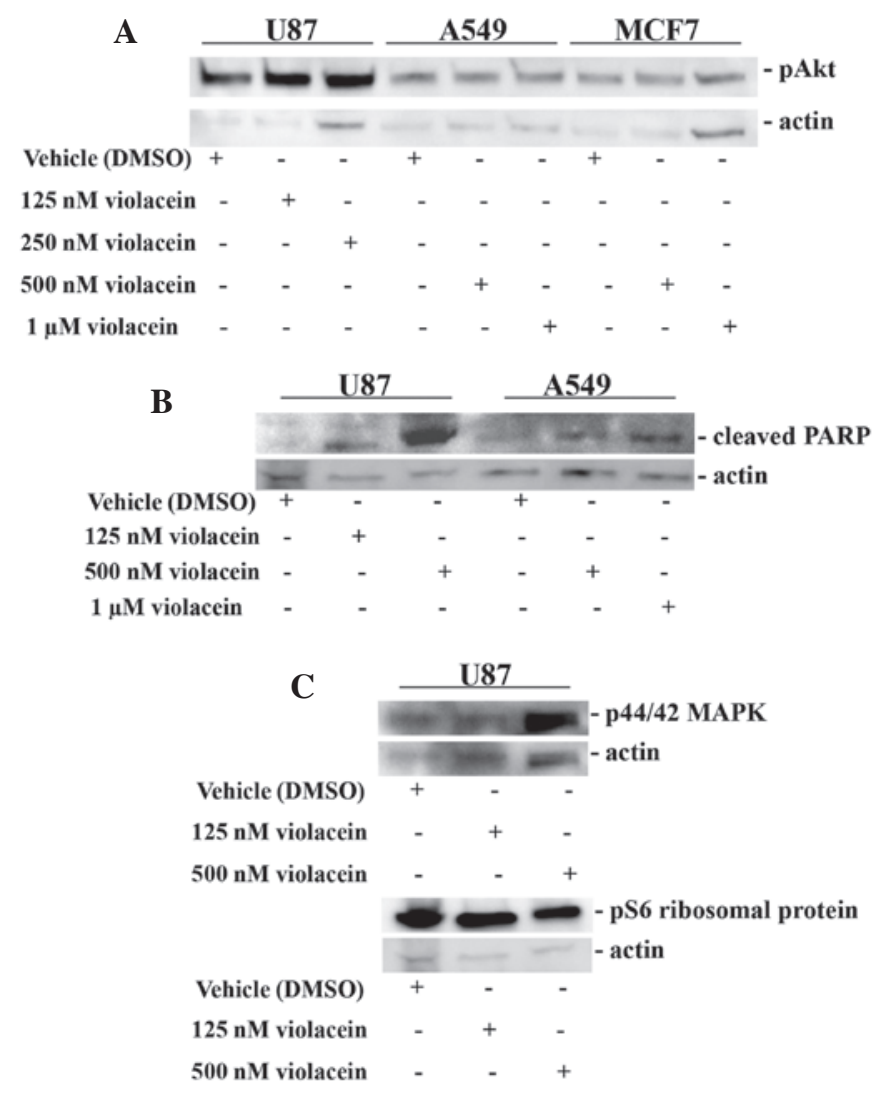

Figure 3. Regulation of survival and apoptotic signaling proteins by violacein. (A) Violacein had no effect on pAkt protein levels in solid tumor cell lines examined, (B) but substantially induced expression of the pro-apoptotic protein cleaved PARP in brain and lung cancer cells. (C) Additionally, violacein upregulated p44/42 MAPK protein levels in brain tumor cells. Immunoblots displayed are representative of at least three independent experiments that showed comparable results.

cancer cells, time course experiments were preformed in the present study. Examination of U87, A549 and MCF7 cells treated with $1 \mu \mathrm{M}$ violacein revealed a reduction in cell proliferation of all three cell lines over a five-day period, with a statistically significant difference $(\mathrm{P}<0.05)$ in cell viability observed on day five between vehicle-treated control cells and violacein-treated cells (Fig. 2). Time course analysis also revealed that U87 and A549 cells were more sensitive to violacein treatment as compared to MCF7 cells, which displayed a two-fold increase in cell viability five days post-violacein treatment as compared to cell viability on day 0 (Fig. 2). These data were consistent with dose response experiments that also showed that U87 and A549 cells were more sensitive to violacein exposure than MCF7 cells. The findings of the present study parallel a study by Menezes et al (34), which showed that crude extracts of violacein were differentially toxic to several human tumor cell lines, including the multi-drug-resistant ovarian tumor cell line NCI/ADR-RES.

Violacein promotes PARP and p44/42 mitogen-activated protein kinase $(M A P K)$ signaling. The mechanistic effects of violacein on cellular responses have proven to be varied and tumor type-specific. Of note, violacein has been shown to upregulate p53, p27 and p21, which are negative regula- 

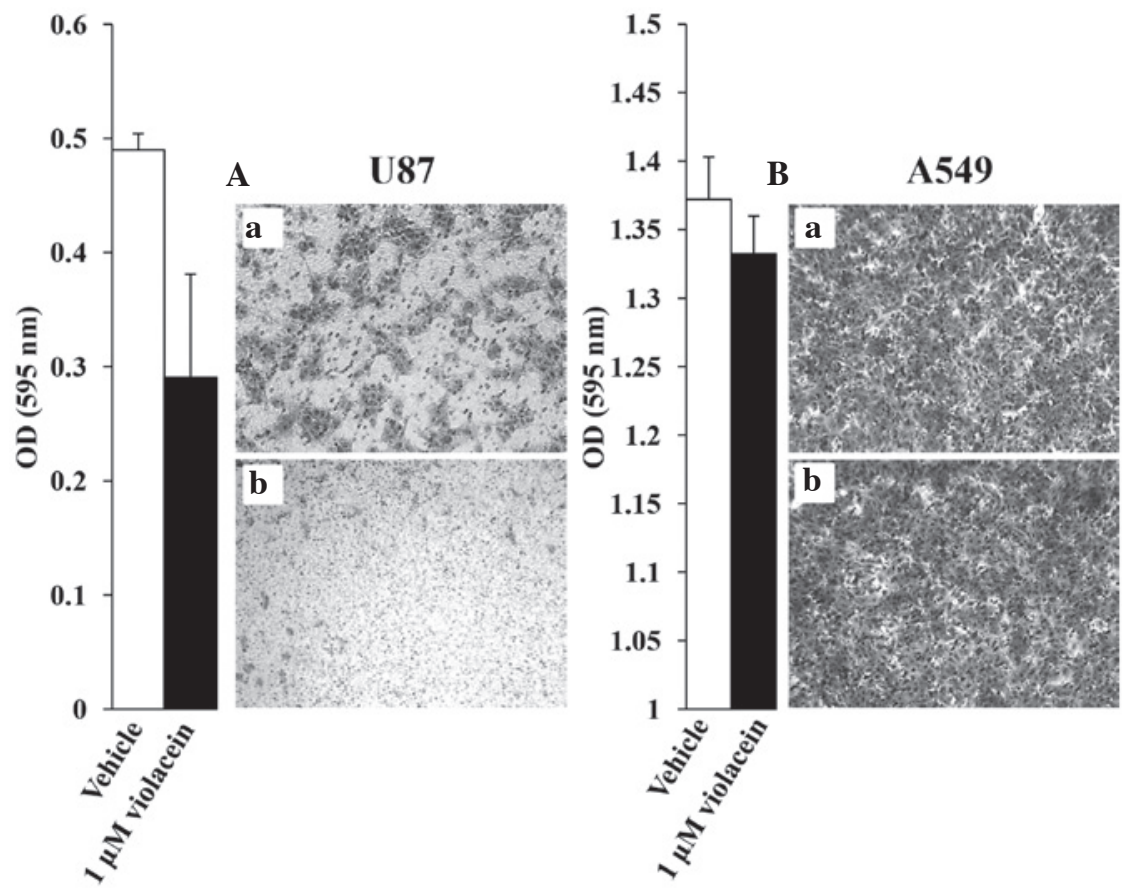

Figure 4. Effects of violacein on tumor cell migration. Violacein (A) considerably reduced brain tumor cell migration and (B) had a diminutive effect on lung cancer cell migration. Shown are boyden chamber assays performed in duplicate that are representative of three independent experiments that exhibited similar results (magnification, 40x). Aa and $\mathrm{Ba}$, cells treated with vehicle dimethylsulfoxide; $\mathrm{Ab}$ and $\mathrm{Bb}$, cells treated with $1 \mu \mathrm{M}$ violacein. OD, optical density.
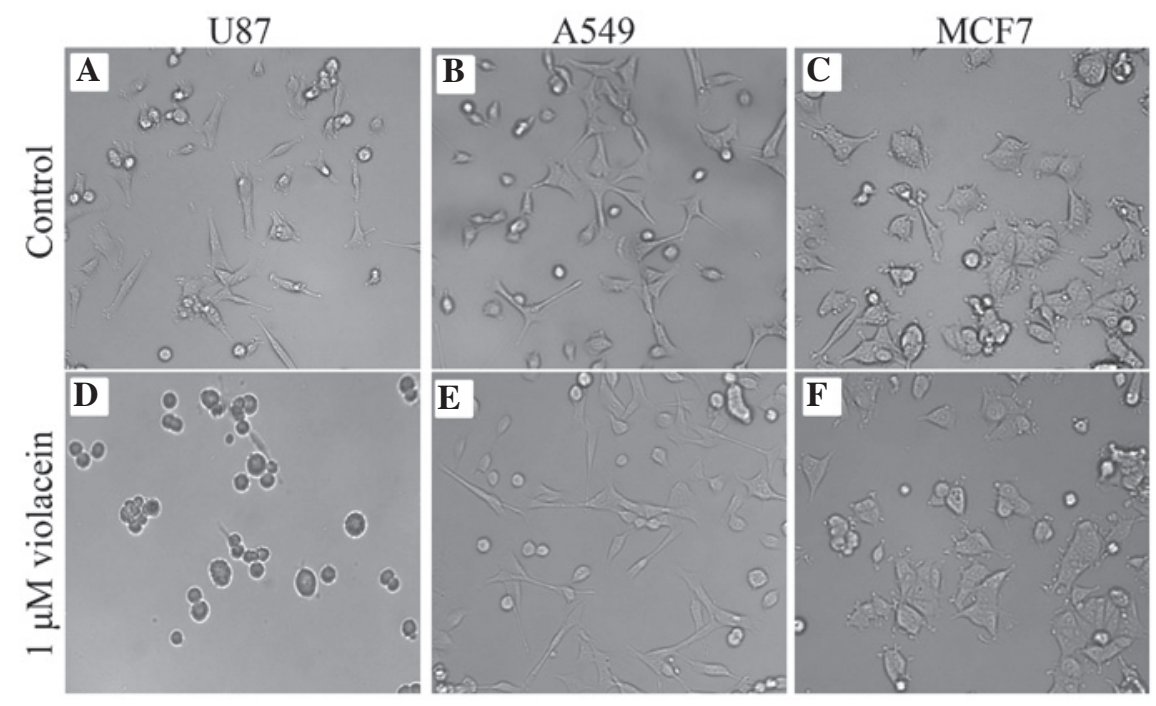

Figure 5. Violacein induces morphological changes that affect tumor cell motility. (A-C) Cells treated with vehicle dimethylsulfoxide. (D) U87 brain tumor cells displayed a transient round cellular phenotype in response to treatment with $1 \mu \mathrm{M}$ violacein, that was absent in (E) lung and (F) breast cancer cells. Micrographs shown are representative of five different experiments that showed similar results (magnification, 100x).

tors of cell cycle progression (24), and to induce reactive oxygen species-mediated apoptotic cell death in colon cancer cells (23). Additionally, Ferreira et al (27) demonstrated that violacein promoted leukemia cell death via tumor necrosis factor signaling. To address the mechanisms of the anti-proliferative response of violacein on solid tumor cells described above, several intracellular signaling proteins were analyzed for changes in their expression when exposed to various concentrations of this agent. The survival and pro-apoptotic proteins, Akt and PARP, were examined in U87, A549 and MCF7 cells exposed to violacein. A substantial induction of cleaved PARP was observed in U87 brain tumor cells treated with $500 \mathrm{nM}$ violacein, as well as in A549 lung cancer cells treated with $1 \mu \mathrm{M}$ violacein (Fig. 3). By contrast, no changes in the activity of Akt expression were observed in cells exposed to violacein (Fig. 3). Additional protein expression analysis revealed that $500 \mathrm{nM}$ violacein upregulated p-44/42 MAPK in U87 cells. This result was similar to that observed in leukemia cells, which displayed increased p38 MAPK expression in response to violacein (27). Furthermore, violacein did not affect the expression levels of pS6 ribosomal protein (Fig. 3), providing additional evidence along with the lack of 
expressional changes of pAkt protein described above, that this secondary metabolite does not mechanistically influence the translational control signaling network.

Impairment of tumor cell migration in response to violacein. The effect of violacein on cellular biological processes that underlie metastatic invasion has not been sufficiently investigated to date, to the best of our knowledge. In the present study, the ability of violacein to inhibit cellular processes that contribute to the metastatic invasion of cancers, which leads to therapeutic resistance and recurrence of this disease, were therefore evaluated. Boyden chamber assays revealed that $1 \mu \mathrm{M}$ violacein decreased the migration of U87 cells by $40 \%$ as compared to that of vehicle-treated control cells, while a diminutive decrease was observed in A549 violacein-treated cells (Fig. 4). The anti-migratory response, particularly of U87 cells, may be attributed in part to violacein-induced morphological changes (Fig. 5). U87 cells exposed to $500 \mathrm{nM}$ violacein appeared to detach from the cell substratum and exhibited a round cellular phenotype three hours post-exposure, which was not observed in A549 and MCF7 cells after treatment with violacein (Fig. 5). However, cell adhesion assays performed revealed that violacein did not affect the adhesive properties of U87 brain tumor cells (data not shown). It should also be mentioned that U87 cells re-attached and displayed normal cell morphology when examined $24 \mathrm{~h}$ after violacein exposure, indicating the violacein-induced morphological changes were not a consequence of cells undergoing cell death. In conclusion, these results suggested that violacein-induced morphological changes had an impact on the migratory ability of U87 brain tumor cells.

\section{Discussion}

The efficacy of therapeutic agents used to treat human cancers is dependent upon their ability to antagonize molecular signaling events that contribute to the survival of tumor cells and induce regulatory mechanisms that promote their death. The present study investigated a novel secondary metabolite, violacein, produced by a chromobacterium, for its utility as an agent that can promote tumor cell death in solid tumor-derived cell lines. It was shown that violacein considerably reduced the proliferative capacity of lung and brain cancer cells, and to a much lesser extent that of breast cancer cells, providing an indication that cancers are differentially sensitive to this agent. This difference in sensitivity and responsiveness was also manifested mechanistically as demonstrated in the ability of violacein to promote apoptotic cell death by upregulating cleaved PARP, a downstream target of the effector pro-apoptotic molecule caspase 3 , in brain and lung cancer cells. Additionally, p44/42, a known apoptosis-promoting regulator and caspase 3 activator, was increased in brain tumor cells treated with violacein. These results established that violacein-induced apoptosis observed in the present study likely occurs via the intrinsic pathway, particularly in brain tumor cells, which is consistent with studies on leukemia, fibrosarcoma and colon cancer cells that have demonstrated the apoptosis-promoting properties of violacein by intrinsic as well as extrinsic pathways $(23,27,35)$. It should also be noted that violacein has been described to elicit other types of cell death, as shown in resistant leukemia cells that underwent cell death as a consequence of endoplasmic reticulum stress and breakdown of the golgi apparatus, underscoring the tumor cell killing capacity of violacein via different cell death mechanisms (25).

Although several studies, including the present study, have provided evidence of violacein's ability to promote tumor cell death, its role as an agent that can prevent the metastatic invasion of cancer cells has received little attention. The present study showed that violacein inhibited brain tumor cell migration, likely as a consequence of disrupting sub-cellular domain structures of the actin filamentous network, including the lamellipodia and filopodia, that led to a round cellular phenotype that compromised the motility of these cells. To the best of our knowledge, the present study was the first to show that violacein inhibits cancer cell migration, extending the anti-malignant properties of this agent. Additionally, the anti-migratory effects of violacein on cancer cells demonstrated in the present study are further supported by a recent study by Platt et al (36), which showed that violacein inhibited the secretion of the pro-cell migratory inflammatory chemokine CXCL12 in breast cancer cells. These results suggested that violacein may have therapeutic applications that prevent brain tumor cells from invading normal brain tissue, as well as inhibit brain metastases from breast cancer, the most common source of metastatic brain tumors in women (30).

In conclusion, violacein has potential as a therapeutic agent to treat cancer due to its versatility to cause cell death in several types of cancer and prohibit metastatic invasion. The potential of violacein to be used as a cancer drug is further supported by the recent U.S. Federal Drug Administration's approval of romidepsin, a histone deactylase inhibitor produced by Chromobacterium violaceum, for the treatment of T-cell lymphoma (37), as well as a renewed interest in cancer therapies utilizing bacteria and bacterial products (1-3) to selectively target cancer cells.

\section{Acknowledgements}

The present study was supported in part by a National Institutes of Health-National Cancer Institute U54 grant (5U54CA163066).

\section{References}

1. Forbes NS: Engineering the perfect (bacterial) cancer therapy. Nat Rev Cancer 10: 785-794, 2010.

2. Patyar S, Joshi R, Byrav DS, Prakash A, Medhi B and Das BK: Bacteria in cancer therapy: A novel experimental strategy. J Biomed Sci 17: 21, 2010.

3. Bernardes N, Seruca R, Chakrabarty AM and Fialho AM: Microbial-based therapy of cancer: Current progress and future prospects. Bioeng Bugs 1: 178-190, 2010.

4. Andrighetti-Fröhner CR, Antonio RV, Creczynski-Pasa TB, Barardi CR and Simões CM: Cytotoxicity and potential antiviral evaluation of violacein produced by Chromobacterium violaceum. Mem Inst Oswaldo Cruz 98: 843-848, 2003.

5. Vaishnav $\mathrm{P}$ and Demain AL: Unexpected applications of secondary metabolites. Biotechnol Adv 29: 223-229, 2011.

6. Ito T, Kawata S, Tamura S, Igura T, Nagase T, Miyagawa JI, Yamazaki E, Ishiguro H and Matasuzawa Y: Suppression of human pancreatic cancer growth in BALB/c nude mice by manumycin, a farnesyl:protein transferase inhibitor. Jpn J Cancer Res 87: 113-116, 1996 
7. Kainuma O, Asano T, Hasegawa M, Kenmochi T, Nakagohri T, Tokoro $\mathrm{Y}$ and Isono K: Inhibition of growth and invasive activity of human pancreatic cancer cells by a farnesyltransferase inhibitor, manumycin. Pancreas 15: 379-383, 1997.

8. Yeung SC, Xu G, Pan J, Christgen M and Bamiagis A: Manumycin enhances the cytotoxic effect of paclitaxel on anaplastic thyroid carcinoma cells. Cancer Res 60: 650-656, 2000.

9. She M, Pan I, Sun L and Yeung SC: Enhancement of manumycin A-induced apoptosis by methoxyamine in myeloid leukemia cells. Leukemia 19: 595-602, 2005.

10. Frassanito MA, Cusmai A, Piccoli C and Dammacco F: Manumycin inhibits farnesyltransferase and induces apoptosis of drug-resistant interleukin 6-producing myeloma cells. Br J Haematol 118: 157-165, 2002.

11. Zhou JM, Zhu XF, Pan QC, Liao DF, Li ZM and Liu ZC: Manumycin inhibits cell proliferation and the Ras signal transduction pathway in human hepatocellular carcinoma cells. Int J Mol Med 11: 767-771, 2003.

12. Zhou JM, Zhu XF, Pan QC, Liao DF, Li ZM and Liu ZC: Manumycin induces apoptosis in human hepatocellular carcinoma HepG2 cells. Int J Mol Med 12: 955-959, 2003.

13. Pan J, Xu G and Yeung SC: Cytochrome c release is upstream to activation of caspase-9, caspase- 8 , and caspase- 3 in the enhanced apoptosis of anaplastic thyroid cancer cells induced by manumycin and paclitaxel. J Clin Endocrinol Metab 86 : 4731-4740, 2001.

14. Ishii T, Hayashi K, Hida T, Yamamoto Y and Nozaki Y: TAN-1813, a novel Ras-farnesyltransferase inhibitor produced by Phoma $\mathrm{sp}$ taxonomy, fermentation, isolation and biological activities in vitro and in vivo. J Antibiot (Tokyo) 53: 765-778, 2000.

15. Nguyen M, Marcellus RC, Roulston A, Watson M, Serfass L, Murthy Madiraju SR, Goulet D, Viallet J, Bélec L, Billot X, et al: Small molecule obatoclax (GX15-070) antagonizes MCL-1 and overcomes MCL-1-mediated resistance to apoptosis. Proc Natl Acad Sci USA 104: 19512-19517, 2007.

16. Pérez-Galán P, Roué G, Villamor N, Campo E and Colomer D: The BH3-mimetic GX15-070 synergizes with bortezomib in mantle cell lymphoma by enhancing Noxa-mediated activation of Bak. Blood 109: 4441-4449, 2007.

17. Trudel S, Li ZH, Rauw J, Tiedemann RE, Wen XY and Stewart AK: Preclinical studies of the pan-Bcl inhibitor obatoclax (GX015-070) in multiple myeloma. Blood 109: 5430-5438, 2007.

18. Fumoleau P, Coudert B, Isambert N and Ferrant E: Nove tubulin-targeting agents: Anticancer activity and pharmacologic profile of epothilones and related analogues. Ann Oncol 18 (Suppl 5): v9-v15, 2007.

19. Nettles JH, Li H, Cornett B, Krahn JM, Snyder JP and Downing KH: The binding mode of epothilone A on alpha, beta-tubulin by electron crystallography. Science 305: 866-869, 2004.

20. Cheng KL, Bradley T and Budman DR: Novel microtubule-targeting agents - the epothilones. Biologics 2: 789-811, 2008.

21. Bollag DM, McQueney PA, Zhu J, Hensens O, Koupal L, Liesch J, Goetz M, Lazarides E and Woods CM: Epothilones, a new class of microtubule-stabilizing agents with a taxol-like mechanism of action. Cancer Res 55: 2325-2333, 1995.

22. Lee FY, Borzilleri R, Fairchild CR, Kim SH, Long BH, Reventos-Suarez C, Vite GD, Rose WC and Kramer RA: BMS-247550: A novel epothilone analog with a mode of action similar to paclitaxel but possessing superior antitumor efficacy. Clin Cancer Res 7: 1429-1437, 2001.
23. de Carvalho DD, Costa FT, Duran N and Haun M: Cytotoxic activity of violacein in human colon cancer cells. Toxicol In Vitro 20: 1514-1521, 2006.

24. Kodach LL, Bos CL, Durán N, Peppelenbosch MP, Ferreira CV and Hardwick JC: Violacein synergistically increases 5-fluorouracil cytotoxicity, induces apoptosis and inhibits Akt-mediated signal transduction in human colorectal cancer cells. Carcinogenesis 27: 508-516, 2006

25. Queiroz KC, Milani R, Ruela-de-Sousa RR, Fuhler GM, Justo GZ, Zambuzzi WF, Duran N, Diks SH, Spek CA, Ferreira $\mathrm{CV}$, et al: Violacein induces death of resistant leukaemia cells via kinome reprogramming, endoplasmic reticulum stress and Golgi apparatus collapse. PLoS One 7: e45362, 2012.

26. Melo PS, Justo GZ, de Azevedo MB, Durán N and Haun M: Violacein and its beta-cyclodextrin complexes induce apoptosis and differentiation in HL60 cells. Toxicology 186: 217-225, 2003.

27. Ferreira CV, Bos CL, Versteeg HH, Justo GZ, Durán N and Peppelenbosch MP: Molecular mechanism of violacein-mediated human leukemia cell death. Blood 104: 1459-1464, 2004.

28. Bromberg N, Dreyfuss JL, Regatieri CV, Palladino MV, Durán N, Nader HB, Haun M and Justo GZ: Growth inhibition and pro-apoptotic activity of violacein in Ehrlich ascites tumor. Chem Biol Interact 186: 43-52, 2010.

29. Rettori D and Durán N: Production, extraction and purification of violacein: an antibiotic pigment produced by Chromobacterium violaceum. World Journal of Microbiology and Biotechnology 4: 685-688, 1998.

30. Stelzer KJ: Epidemiology and prognosis of brain metastases. Surg Neurol Int 4 (Suppl 4): S192-S202, 2013.

31. Melo PS, De Azevedo MM, Frungillo L, Anazetti MC, Marcato PD and Duran N: Nanocytotoxicity: Violacein and violacein-loaded poly (D,L-lactide-co-glycolide) nanoparticles acting on human leukemic cells. J Biomed Nanotechnol 5: 192-201, 2009.

32. Melo PS, Maria SS, Vidal BC, Haun M and Durán N: Violacein cytotoxicity and induction of apoptosis in V79 cells. In Vitro Cell Dev Biol Anim 36: 539-543, 2000.

33. Saraiva VS, Marshall JC, Cools-Lartigue J and Burnier MN Jr: Cytotoxic effects of violacein in human uveal melanoma cell lines. Melanoma Res 14: 421-424, 2004.

34. Menezes CB, Silva BP, Sousa IM, Ruiz AL, Spindola HM, Cabral E, Eberlin MN, Tinti SV, Carvalho JE, Foglio MA, et al: In vitro and in vivo antitumor activity of crude extracts obtained from Brazilian Chromobacterium sp isolates. Braz J Med Biol Res 46: 65-70, 2013

35. Mojib N, Nasti TH, Andersen DT, Attigada VR, Hoover RB, Yusuf $\mathrm{N}$ and Bej AK: The antiproliferative function of violacein-like purple violet pigment (PVP) from an Antarctic Janthinobacterium sp. Ant5-2 in UV-induced 2237 fibrosarcoma. Int J Dermatol 50: 1223-1233, 2011.

36. Platt D, Amara S, Mehta T, Vercuyssee K, Myles EL, Johnson T and Tiriveedhi V: Violacein inhibits matrix metalloproteinase mediated CXCR4 expression: Potential anti-tumor effect in cancer invasion and metastasis. Biochem Biophys Res Commun 455: 107-112, 2014.

37. VanderMolen KM, McCulloch W, Pearce CJ and Oberlies NH: Romidepsin (Istodax, NSC 630176, FR901228, FK228, depsipeptide): A natural product recently approved for cutaneous T-cell lymphoma. J Antibiot (Tokyo) 64: 525-531, 2011 